\title{
Polyanions in Coagulation and Thrombosis: Focus on Polyphosphate and Neutrophils Extracellular Traps
}

\author{
Chandini Rangaswamy ${ }^{1, *}$ Hanna Englert ${ }^{1, *}$ Carsten Deppermann ${ }^{1} \quad$ Thomas Renné $^{1}$ \\ ${ }^{1}$ Institute of Clinical Chemistry and Laboratory Medicine, University \\ Medical Center Hamburg-Eppendorf, Hamburg, Germany \\ Thromb Haemost 2021;121:1021-1030.

\begin{abstract}
Address for correspondence Thomas Renné, MD, PhD, Institute of Clinical Chemistry and Laboratory Medicine (O26), University Medical Center Hamburg-Eppendorf, Martinistrasse 52, D-20246 Hamburg, Germany (e-mail: thomas@renne.net).
\end{abstract}

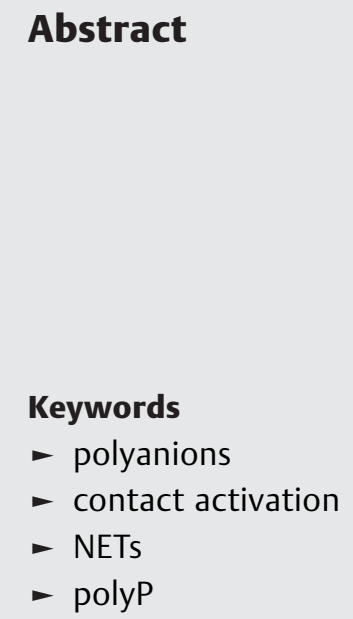

Neutrophil extracellular traps (NETs) and polyphosphates (polyP) have been recognized as procoagulant polyanions. This review summarizes the activities and regulation of the two procoagulant mediators and compares their functions. NETs are composed of DNA which like polyP is built of phosphate units linked by high-energy phosphoanhydride bonds. Both NETs and polyP form insoluble particulate surfaces composed of a DNA/histone meshwork or $\mathrm{Ca}^{2+}$-rich nanoparticles, respectively. These polyanionic molecules modulate coagulation involving an array of mechanisms and trigger thrombosis via activation of the factor XII-driven procoagulant and proinflammatory contact pathway. Here, we outline the current knowledge on NETs and polyP with respect to their procoagulant and prothrombotic nature, strategies for interference of their activities in circulation, as well as the crosstalk between these two molecules. A better understanding of the underlying, cellular mechanisms will shed light on the therapeutic potential of targeting NETs and polyP in coagulation and thrombosis.

\section{Physiological Polyanions}

Biological polyanions are highly abundant, negatively charged molecules that exist ubiquitously in various forms in nature. For decades it has been established that polyanions participate in blood coagulation and exert either procoagulant or anticoagulant activities that contribute to normal hemostasis or pathological thrombosis, respectively. Polyanionic carbohydrates, glycosaminoglycans (GAGs) provide anticoagulant activities on the cell surface of most eukaryotic cells. Heparan-, chondroitin-, and dermatan-sulfate-type GAGs interfere with clot formation at the interface of blood and vascular cells by amplifying antithrombin and heparin cofactor II activities. ${ }^{1}$ Mast cell-derived heparin shares structural similarity with heparan sulfate. Unfractionated heparin, low-molecular weight heparin, and heparin-derived agents are commonly used ther-

* These two authors contributed equally to this work.

apeutically as injectable anticoagulants. ${ }^{2}$ In contrast to negatively charged polysaccharides, DNA, a key component of neutrophil extracellular traps (NETs), and polyphosphate (pol$\mathrm{yP}$ ) have procoagulant activities and promote blood clotting with implications for thrombosis (-Fig. 1).

\section{Extracellular DNA}

Circulating extracellular DNA in human plasma was described as early as $1948 .^{3}$ In response to stimulation, an array of cells, including leukocytes, mast cells, senescent cells, and tumor cells, release their DNA into the extracellular space either as chromatin (histones complexed with DNA), naked doublestranded DNA (dsDNA), or mitochondrial DNA. ${ }^{4}$ In addition to actively released nucleic acids, DNA from disintegrating bacteria and viruses is also detectable in circulation. ${ }^{5}$ Small amounts of extracellular DNA are present in plasma and serum of healthy individuals; however, levels are largely elevated in

(c) 2020. Thieme. All rights reserved. Georg Thieme Verlag KG,

Rüdigerstraße 14,

70469 Stuttgart, Germany
DOI https://doi.org/ 10.1055/a-1336-0526. ISSN 0340-6245. accepted after revision

December 4, 2020

published online

December 11, 2020 

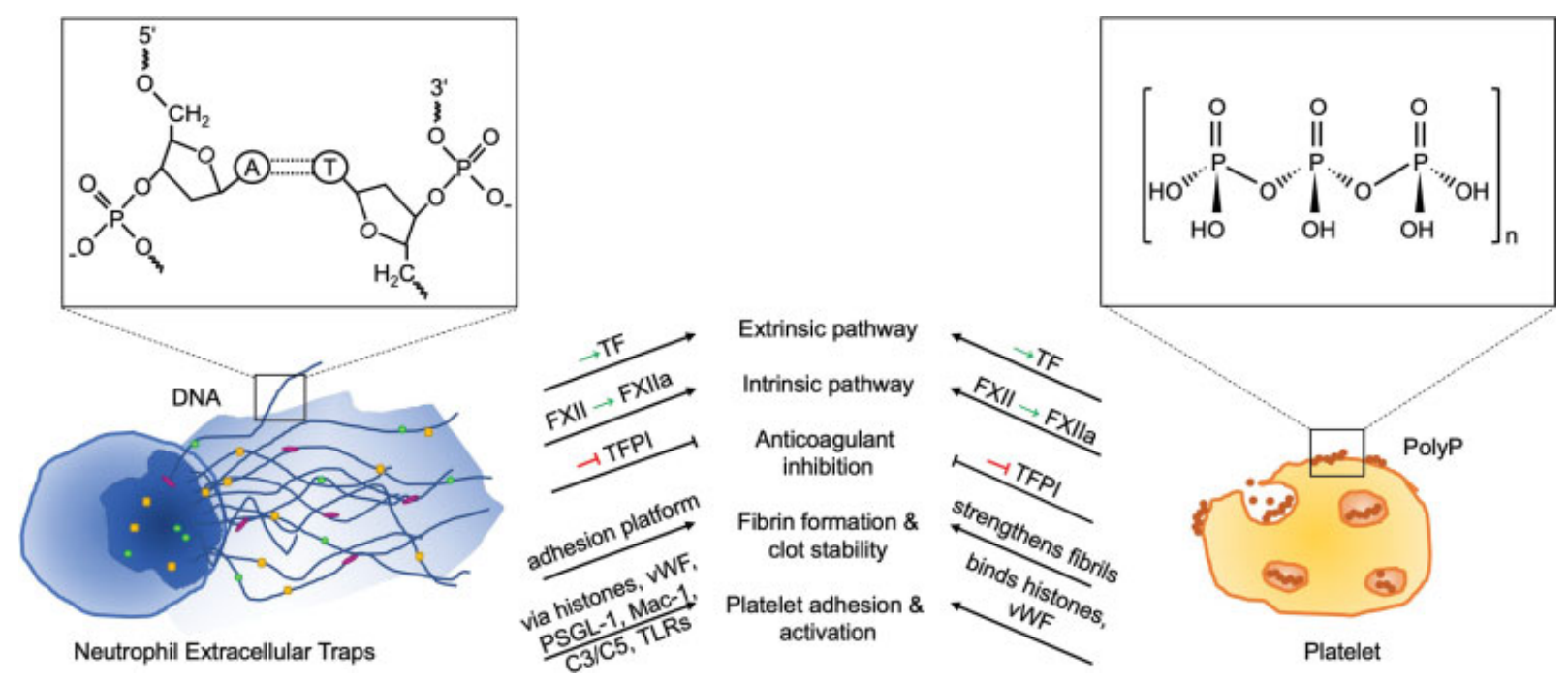

Fig. 1 Common mechanistic and structural features of NETs and platelet polyP. The lower part of the left image shows a neutrophil that is releasing NETs (depicted by long, dark blue DNA strands entangled with histones and other granular proteins) and the right-hand side shows a platelet decorated with polyP on its surface. PolyP can be composed of a few hundreds to thousands of phosphate units, which also make up the phosphate backbone of DNA. The phosphate backbone serves as a structural support and energy source for both of these molecules. NETs and polyP are polyanionic, immunomodulatory structures that can activate platelets, FXII, and other factors of the contact pathway, which will lead to further downstream events of the coagulation cascade. Eventually, NETs and polyP can interact with fibrin and fibrinogen, reinforcing the fibrin meshwork. C3/C5, complement components; FXII, factor XII; FXIla, activated FXII; Mac-1: macrophage-1 antigen/CD11b/CD18; NET; neutrophil extracellular trap; polyP, polyphosphate; PSGL-1: P-selectin glycoprotein ligand-1; TF: tissue factor; TFPI: tissue factor pathway inhibitor; TLR: toll-like receptor; vWF, von Willebrand factor.

pathological conditions, suggesting the use of extracellular DNA as a prognostic biomarker. ${ }^{6-10}$

Neutrophils are the predominant leukocyte in human blood and present the major source of extracellular DNA. In response to various inflammatory stimuli, activated neutrophils cast out their DNA, forming NETs. NETs were originally described as components of the innate immune response to microbial infections that trap invading microorganisms, thus interfering with pathogen dissemination. Furthermore, it has been shown that inducers of phagocytosis trigger NET formation suggesting a cooperative effect of NETosis and phagocytosis in host defense. ${ }^{11}$ NETs are composed of long DNA strands that are bound to histones and neutrophil granular-derived proteins. ${ }^{12}$ DNAintercalating dyes stain NETs; however, the signal is lost upon efficient digestion by deoxyribonuclease-1 (DNase1) indicating that polyanionic dsDNA is the major component of NETs. ${ }^{13}$ Since their discovery, NETs have been implicated in a plethora of pathophysiologic conditions offering a novel link between inflammation and thrombosis in an emerging field in biomedicine. ${ }^{14-16}$

NET formation is a multistep process (-Table $\mathbf{1}$ ). Upon neutrophil activation, nuclear chromatin starts to decondense, leading to a loss of the typical lobulated morphology of the neutrophils' nucleus. During classical NET formation, the multimeric NADPH-oxidase assembles on cellular membranes and produces reactive oxygen species, which in turn activate the enzyme peptidyl-arginine deiminase 4 (PAD4). ${ }^{17,18}$ PAD4 citrullinates histones, neutralizing their net positive charge and thus reducing their affinity for binding to the negatively charged DNA polyanion, thereby facilitating chromatin decondensation. ${ }^{18}$ Additionally, neutrophil elastase (NE) and myeloperoxidase (MPO) are released from neutrophil granules and translocate to the nucleus, where they degrade histones and promote further unfolding of chromatin. ${ }^{19}$ Consequently, the nuclear membrane breaks up, and chromatin is released into the cytosol, where it binds to granular and cytosolic proteins. The mechanism by which the plasma membrane ruptures to release NETs is not completely understood; however, recent studies indicate that the pore-forming protein gasdermin $\mathrm{D}$ might play a role. ${ }^{20}$

The extracellular DNA forms supramolecular web-like structures both in the vasculature and surrounding tissues. ${ }^{17}$ High-resolution scanning electron microscopy (SEM) revealed that NETs are made of fine thread-like structures, composed of long and sticky DNA strands. ${ }^{13}$

\section{Polyphosphate}

In contrast to NETs, polyP is a purely inorganic polymer composed of linear chains of orthophosphates that are connected by energy-rich phosphoanhydride bonds (-Table 1). PolyP is abundant in the environment, synthetic polyP is used in multiple technical processes (e.g., as water softener, food ingredient, or fire extinguisher), and physiological polyP is found in every cell in nature. The polymer is evolutionarily conserved among bacterial, fungal, plant, and animal cells. ${ }^{21}$ The high-energy phosphoanhydride bonds in the polyP chain are equivalent to those in ATP and bacteria and yeast use the polymer as a chemical energy storage pool during starvation and environmental stress. ${ }^{22}$

Prokaryotic and lower eukaryotic microorganisms have intracellular polyP molecules ranging in chain length from a few hundreds to thousands of phosphate units. The polymer is stored in subcellular organelles called acidocalcisomes, along 
Table 1 Formation, binding partners, cellular origin, detection, and degradation of neutrophil extracellular traps and polyphosphate

\begin{tabular}{|c|c|c|}
\hline & Neutrophil extracellular traps & Polyphosphate \\
\hline Formation & $\begin{array}{l}\text { - Microbial/inflammatory stimuli such as LPS, TLRs, } \\
\text { cytokine, Fc, or complement receptors }{ }^{13,112-114} \\
\text { - Synthetic compounds like phorbol myristate ace- } \\
\text { tate (PMA), A23187, or ionomycin } 114,115 \\
\text { - Platelet neutrophil interaction } 113\end{array}$ & $\begin{array}{l}\text { - Polyphosphate kinase } 1 \text { and } 2 \text { (PPK1, PPK2) and } \\
\text { homologs, e.g., DdPPK } 71,116 \\
\text { - Vacuolar transporter chaperone cleaves } \\
\text { ATP Y-phosphate residues } 117 \\
\text { - Formation and secretion are induced by agonists } \\
\text { such as thrombin, thrombin receptor-activating } \\
\text { peptide } 6 \text { (Trap6), collagen, and ADP } 31\end{array}$ \\
\hline $\begin{array}{l}\text { Binding } \\
\text { partners }\end{array}$ & 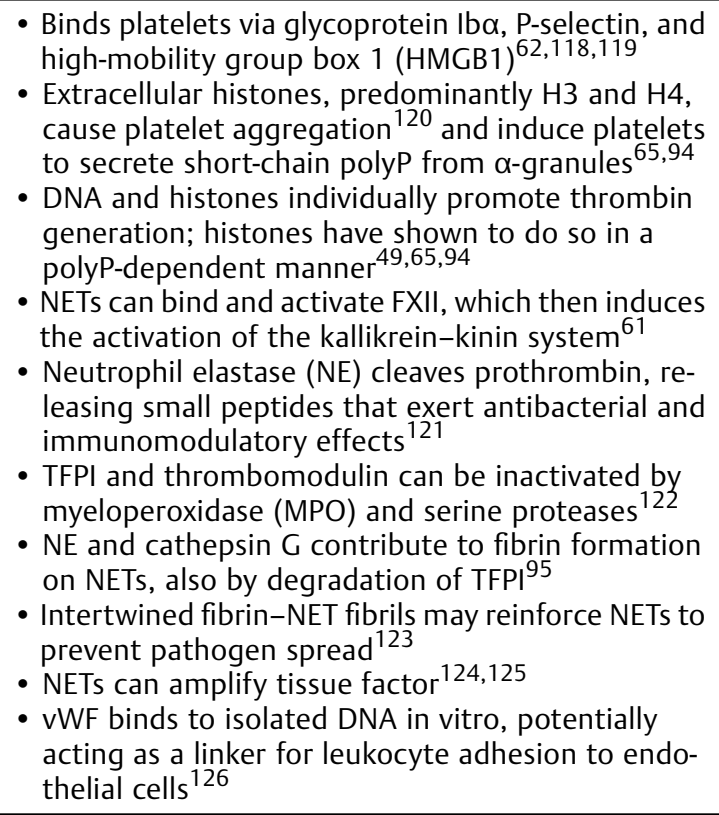 & $\begin{array}{l}\text { - Accelerates the generation of FXIa and thrombin }{ }^{127} \\
\text { - Amplifies thrombin-mediated activation of FXI }{ }^{128} \\
\text { - Accelerates FV activation by FXa and thrombin }{ }^{128} \\
\text { - Enhances the binding of platelets to von Willebrand } \\
\text { - factor }{ }^{129} \\
\text { - Activates FXII }{ }^{127} \text { thereby also triggering } \\
\text { inflammation via FXIla-mediated activation of the } \\
\text { kallikrein-kinin system }{ }^{52} \\
\text { - Inactivates TFPI, abrogating its anticoagulant func- } \\
\text { - Iion }{ }^{130} \\
\text { - } \text { resistant to fibrinolysis }^{131} \\
\text { Binds extracellular histones and activates } \\
\text { platelets }\end{array}$ \\
\hline $\begin{array}{l}\text { Cellular } \\
\text { origin }\end{array}$ & $\begin{array}{l}\text { - Leukocytes } s^{13,133} \\
\text { - Mast cells } s^{134} \\
\text { - Tumor cells }\end{array}$ & $\begin{array}{l}\text { - Ubiquitously found in various species including } \\
\text { bacterial, plant, and mammalian cells } s^{21} \\
\text { - Platelet dense granules }{ }^{29} \\
\text { - Mast cells } s^{34} \\
\text { - Astrocytes }{ }^{135} \\
\text { - Tumor cells }\end{array}$ \\
\hline Detection & $\begin{array}{l}\text { - } \text { Microscopy }^{13} \\
\text { - Flow cytometry } \\
\text { - } \text { Flow chamber }^{113} \\
\text { - } \text { ELISA }^{82} \\
\text { - Western blotting } \\
\text { - Sytox Green/PicoGreen staining }\end{array}$ & $\begin{array}{l}\text { - DAPI, Hoechst } 33342 \text {, toluidine blue } \mathrm{O} \text {, } \\
\text { methylene blue, tetracycline, neutral red, } \\
\text { malachite green }{ }^{85-87} \\
\text { - Flow cytometry }{ }^{79,87} \\
\text { - Urea-polyacrylamide gel electrophoresis } \\
\text { - Chromatography } \\
\text { - }{ }^{84} \text { P-NMR } \\
\text { - Fourier transform-infrared (FT-IR) } \\
\text { - Mass spectrometry } \\
\text { - }{ }^{84} \\
\text { Microscopy }\end{array}$ \\
\hline Degradation & $\begin{array}{l}\text { - Endonucleases DNase } 1 \text { and DNase } 1 \text { like- } 3^{59} \\
\text { - Human monocyte-derived macrophages and den- } \\
\text { dritic cells }{ }^{69,70} \\
\text { - Opsonization by complement factors }\end{array}$ & $\begin{array}{l}\text { - Endopolyphosphatases, e.g., Ppn1, Ppn2, } \\
\text { Ddp1 } 74,75,136 \\
\text { - Exopolyphosphatases, e.g., Ppx1 } 1^{72,73} \\
\text { - Diphosphoinositol polyP phosphohydrolases } \\
\text { (DIPPs) may degrade polyP in mammals } 76\end{array}$ \\
\hline
\end{tabular}

Abbreviations: DAPI, 4',6-diamidino-2-phenylindole; ELISA, enzyme-linked immunosorbent assay; LPS; lipopolysaccharides; NET; neutrophil extracellular trap; ${ }^{32} \mathrm{P}-\mathrm{NMR}$, phosphorus-31 nuclear magnetic resonance; polyP, polyphosphate; TFPI, tissue factor pathway inhibitor; TLR: toll-like receptor; vWF, von Willebrand factor.

with high concentrations (in the molar range) of divalent metal cations, mostly $\mathrm{Ca}^{2+}$ but also $\mathrm{Mg}^{2+}$ and $\mathrm{Zn}^{2+} \cdot{ }^{21} \mathrm{Ca}^{2+}$-ions bind to the phosphate units in the polyP backbone with high affinity. In vivo, physiological polyP is complexed with metal ions. Ion-bound polyP has a different structure and biophysical properties. $\mathrm{Ca}^{2+}$-polyP has little if any solubility in plasma, challenging the predictive value of coagulation studies based on soluble synthetic polyP. Despite detailed information on polyP metabolism in yeast, not much is known about polyP regulation in mammals. The polymer is enriched in various 
subcellular compartments including lysosomes, mitochondria, and nuclei; however, it is also found in association with the cytoskeleton and in the cytoplasm. Some cells such as astrocytes, mast cells, tumor cells, and platelets have the capacity to actively release polyP from secretory vesicles. ${ }^{23-28}$ Platelet dense granules are specialized secretory organelles similar to acidocalcisomes found in microorganisms. Dense granules appear as dark vesicles in electron microscopy images because of their high local concentration of polyP $(\sim 130 \mathrm{mM})$ that is complexed with $\mathrm{Ca}^{2+}, \mathrm{Mg}^{2+}$, and $\mathrm{Zn}^{2+}$ ions. ${ }^{29,30}$

\section{PolyP in Blood Coagulation}

Patients with a defect in platelet dense granules show significantly lower polyP levels and defective factor XII (FXII)-dependent clotting in platelet-rich plasma (PRP; Hermansky-Pudlak syndrome, delta storage pool diseases, Chediak-Higashi syndrome). ${ }^{24,31,32}$ The addition of exogenous polyP to PRP of Hermansky-Pudlak syndrome patients restores their clotting capacity, consistent with the notion that platelet polyP triggers coagulation in a FXII-dependent manner. ${ }^{31}$ Yeast cells lacking inositol hexakisphosphate kinase (a key enzyme involved in polyP synthesis) are devoid of polyP. Consistently, platelets of inositol hexakisphosphate kinase-1-deficient $\left(I p 6 k 1^{-/-}\right)$mice have reduced polyP levels, compromised FXII-triggered coagulation, and are protected from platelet-driven lethal pulmonary embolisms. ${ }^{33}$ In addition to defective polyP levels, Ip $6 \mathrm{k}^{-{ }^{--}}$mice show an array of other severe phenotypes including infertility and heart problems making them a challenging model to study platelet polyP in vivo. Xenotropic and polytropic retrovirus receptor 1 (XPR1) is a transmembrane protein that was originally described as a cellular docking site for retroviruses but also functions as a phosphate exporter. Recent systems biology-based studies have identified XPR1 as the major, if not exclusive, phosphate exporter in platelets. Pharmacologic and genetic targeting of XPR1 activity increased intracellular phosphate levels and led to polyP accumulation. Conditional ablation of the Xpr1 gene in mouse platelets accelerated arterial thrombosis and activated platelet-driven pulmonary embolism, but did not affect hemostasis. ${ }^{34}$ The data identify XPR1 as the first specific regulator of polyP in platelets and possibly other cells and indicate a fundamental role of phosphate metabolisms for thromboembolic diseases.

For years, it was believed that platelets secrete soluble short-chain 50-100mer polyP upon activation. However, this hypothesis was based on polymer purifications from the supernatant of activated platelets using a phenol-chloroform extraction method that selects for short-chain water soluble molecules. ${ }^{31}$ Follow-up studies using anion-exchange isolation methods from complete cell lysates confirmed the presence of small amounts of short-chain polyP in platelets. Additionally, it was revealed that, similar to other mammalian cells, the vast majority of platelet polyP consists of long-chain polymers. As platelets store polyP together with high concentrations of $\mathrm{Ca}^{2+}$ ions in dense granules, the released polyP is complexed with calcium. ${ }^{35} \mathrm{Ca}^{2+}$-polyP has a very low solubility and readily precipitates into nanoparticles independent of its chain length. ${ }^{36}$ PolyP nanoparticles are stable in physiologic buffers for several hours. ${ }^{37}$ Real-time imaging using polyPspecific probes showed that only minor portions of the soluble polyanion fraction are released into the supernatant while the majority remains anchored to the platelet plasma membrane. ${ }^{38,39}$ Flow cytometry-based methods have been established to quantify polyP on the surface of activated platelets suggesting a potential use of polyP as a biomarker in thrombotic diseases. ${ }^{40}$ Platelet-bound polyP nanoparticles drive coagulation in a FXII-dependent manner, while soluble polymers have the capacity to drive other FXII-independent coagulation reactions. Consistent with the notion that polyP operates by activating FXII, a series of classical studies has shown the contribution of FXII in activated platelet-driven coagulation/clot formation. ${ }^{41-44}$ Vice versa, ablation of FXII or polyP impairs platelet-driven thrombosis in murine models. $^{33,45,46}$

\section{NETs in Blood Coagulation}

Similar to polyP, multiple in vivo studies have shown NETs to be implicated in thrombotic and inflammatory reactions. ${ }^{47-54}$ Following vascular injury, neutrophils immediately migrate to the lesion site preceding platelets. ${ }^{50}$ At the site of injury, activated platelets and endothelial cells activate neutrophils to induce NET formation (NETosis). NETs in turn stimulate platelet aggregation and trigger fibrin formation in vitro. ${ }^{48}$ NETs are abundant in thrombi from experimental animal models and infusion of DNase interferes with thrombus formation. ${ }^{48,55}$ NETs are also enriched in venous and arterial thrombi of patients who suffered from a heart attack, ${ }^{56}$ stroke, ${ }^{57}$ and peripheral vascular arterial occlusions. ${ }^{58}$ Furthermore, it has been shown that NETs alone are sufficient for vascular occlusions under septic conditions in the absence of host enzymes DNase1 and DNase1L3. ${ }^{59}$ High levels of NET biomarkers, such as DNA/histones complexes, MPO, and S100A8/A9, are detectable in plasma from patients with thrombotic microangiopathy, indicating that the ineffective clearance of NETs contributes to the mechanisms of the occlusive disease. ${ }^{55,60}$ Various components of NETs have been identified as initiators or propagators of coagulation activity, including histones and granule proteins. Soluble DNA purified from neutrophils, as well as NETs (induced by glucose oxide or interleukin-8 [IL-8] stimulation), can assemble and activate FXII in vitro. ${ }^{61}$ SEM of NETs induced by platelet-activated neutrophils showed that the DNA backbone of NETs binds FXII and its substrate of the intrinsic coagulation pathway, factor XI (FXI). ${ }^{62}$ However, whether NETs directly trigger FXII contact activation or merely act as a scaffold for the assembly of FXII activators and coagulation factors is still unclear. ${ }^{63}$ Thrombin generation triggered by the addition of NETs is reduced in FXII- and FXI-deficient plasma, indicating that the procoagulant activity of NETs is mediated by the FXII-FXI axis at least in vitro. ${ }^{49}$ Besides contact-activating FXII, DNA acts as a surface in thrombin-dependent FXI activation. ${ }^{64}$

Many of the studies on the procoagulant nature of NETs examined purified NET DNA and the various components of NETs individually, and thus the overall procoagulant activity 
of NETs was largely omitted. Recently it was shown that human neutrophil-purified DNA and recombinant histones $\mathrm{H} 3$ and H4 triggered coagulation in plasma individually, whereas intact NETs did not. Histone-histone and histoneDNA interactions within the nucleosome unit and supercoiled chromatin in NETs neutralize the negative charges of the polyanion and thereby dampen the procoagulant activity of NET-DNA. ${ }^{65}$ The precise mechanisms of NETs in thrombus formation are the subject of ongoing studies; however, NETs appear to stimulate both platelets and the coagulation system. ${ }^{49}$

\section{Degradation of NETs and polyP}

Despite their functional and structural similarities, the degradation pathways of NETs and polyP seem to be quite different. Defective NET clearance triggers proinflammatory and autoimmune conditions; however, the underlying mechanisms are still under investigation. Degradation of NETs is an intricate process involving the activity of various enzymes. While endonucleases efficiently degrade extracellular DNA, other NET components such as histones and NE remain intact in a murine model of bacterial infection. ${ }^{66}$ Although coagulation inhibitor activated protein C (APC) cleaves histones and interferes with their cytotoxic activity in a purified system, it has no effect on NET-induced cytotoxicity suggesting that histone-dependent cytotoxicity is protected from APC degradation. ${ }^{67,68}$

Complete degradation of NETs in vivo requires the concerted activity of two secreted host endonucleases, DNase1 and DNase1-like 3. ${ }^{59}$ The reconstitution of either DNase 1 or DNase1-like 3 was sufficient to rescue the lethal phenotype of a chronic inflammation model in Dnase $1^{-1-}$ |Dnase1like $3^{-1-}$ mice. In addition to extracellular DNases, the cytosolic exonuclease TREX1 (DNase III) has the capacity of clearing NETs in vitro. ${ }^{69}$ Furthermore, NETs can be engulfed by monocyte-derived macrophages and dendritic cells in a cytochalasin D-dependent manner, implying a role of active endocytosis in NET clearance. ${ }^{69,70}$ Following internalization by macrophages, NETs are degraded in lysosomal compartments in an immunologically silent manner. Hence, NET clearance does not evoke the release of proinflammatory cytokines, maintaining homeostasis in tissues. ${ }^{70}$

In contrast to NETs, not much is known about polyP metabolism in mammalian systems. In prokaryotes polyP is synthesized by polyP kinase (PPK), which reversibly transfers $\gamma$-phosphate units from ATP and guanosine diphosphate onto the polymer chain. ${ }^{22,71}$ Depolymerization of polyP into free $\mathrm{P}_{\mathrm{i}}$ residues is catalyzed by exopolyphosphatase $(\mathrm{Ppx}){ }^{72}$ Three distinct polyP phosphatases have been described in Saccharomyces cerevisiae: exopolyphosphatase [Ppx1], endopolyphosphatases [Ppn1], and diadenosine and diphosphoinositol phosphohydrolase [Ddp1]. ${ }^{73-75}$ Mammalian homologs for these polyP phosphatases have not yet been identified; however, diphosphoinositol polyP phosphohydrolases seem to participate in polyP degradation under alkaline conditions. ${ }^{75}$ Mammalian alkaline phosphatase (AP) from calf intestine is a potent exopolyphosphatase and cleaves polyP. ${ }^{76} \mathrm{Ca}^{2+}$-polyP has a half-life in plasma of approximately 90 minutes, before it gets degraded by polyphosphatases, such as AP. Exopolyphosphatase (Ppx1)-mediated degradation of polyP improved cardiomyocyte function in cell culture ${ }^{77}$ and alleviated $\mathrm{Ca}^{2+}$ accumulation in mitochondria and $\mathrm{Ca}^{2+}$-induced cell death processes related to myocardial infarction and ischemia-reperfusion injury.

Extracellular RNA is considered to promote blood coagulation based on the fact that infusion of RNase interferes with arterial thrombosis in a murine $\mathrm{FeCl}_{3}$-driven vascular injury model. ${ }^{78}$ RNase readily hydrolyzes polyP, offering an alternative explanation for the thromboprotective effects conferred by the enzyme. ${ }^{79}$

\section{Detection of polyP and NETs}

NETs and polyP are detected by similar dyes and techniques. Imaging of NETs in vitro is mainly based on immunofluorescence microscopy, transmission electron microscopy, and SEM. The DNA-intercalating dyes SYTOX Green/PicoGreen and 4',6-diamidino-2-phenylindole (DAPI), as well as antibodies against NET-specific structures such as citrullinated histones (H3cit) and histone-MPO complexes are typically used for microscopy. ${ }^{13}$ In recent years, the occasional bias in microscopic imaging of NETs has been criticized, hence more automated software tools for image-based NET quantification are currently being developed. ${ }^{80}$ Granular proteins and other NET components can also be targeted with flow cytometry, Western blotting, and enzyme-linked immunosorbent assays. ${ }^{19,81,82}$ To further standardize quantification of NETs, especially in clinical settings, the ISTH (International Society on Thrombosis and Haemostasis) Vascular Biology Subcommittee has recently started a collaborative effort to investigate and harmonize NET quantification techniques. Despite successful imaging of NETs in vitro, visualization of the polyanion in vivo still poses significant hurdles. However, during the last few years, imaging by intravital microscopy has strongly facilitated the in vivo evaluation of NET formation and degradation. ${ }^{64,83}$

PolyP can be stained with dyes such as toluidine blue $\mathrm{O}$ or methylene blue to be visualized by phase-contrast, brightfield, and electron microscopy. ${ }^{79}$ Because polyP is mainly stored in membrane-enclosed compartments in eukaryotes, the dyes neutral red and tetracycline can detect polyP with nondestructive methods, such as light microscopy and flow cytometry. ${ }^{84}$ Similarly to NETs, DNA-intercalating dyes such as DAPI ${ }^{85}$ and Hoechst $33342^{86}$ stain polyP. However, DAPI bound to polyP emits a bright yellow-green fluorescence, distinct from the blue fluorescence emitted by DNA. ${ }^{87}$ Toluidine blue $O$ and DAPI only detect polyP with a chain length longer than 15-mers. ${ }^{88,89}$ Sophisticated flow cytometry analyses using DAPI or tetracycline staining ${ }^{87}$ or recombinant polyP-specific probes based on the polyP-binding domain of Escherichia coli exopolyphosphatase ${ }^{40}$ are also being employed.

Malachite green dye binds free orthophosphates and can be used to quantify phosphate monomers in solution. ${ }^{79}$ 
Degradation of polyP with Ppx, allows for quantifying polyP concentration. The malachite green assay fails to detect the chain length of the polyanion; however, it has a high sensitivity and measures polyP up to the picomolar range. As Ppx only digests polyP with a chain length of greater than 38 phosphate subunits, the malachite green assay is insensitive for short-chain polyP. PolyP can furthermore be visualized by microscopy, ${ }^{79}$ electrophoresis, chromatography, ${ }^{32} \mathrm{P}-\mathrm{NMR}$, Fourier transform-infrared, and mass spectrometry. ${ }^{84}$

\section{Crosstalk of NETs and polyP}

Inflammation and thrombosis are mediated by a complex interplay involving neutrophils and platelets. During coagulation, FXII is activated by a unique mechanism triggered by binding ("contact") to negatively charged polyanionic surfaces ("contact activation"). Activated FXII initiates the intrinsic pathway of coagulation and the bradykinin-producing kallikrein-kinin system, leading to coagulation and inflammation. ${ }^{90-92}$ Extracellular DNA and polyP activate FXII and promote thrombosis by the intrinsic pathway of coagulation in vivo. ${ }^{87,93,94}$

While polyP initiates coagulation via FXII, NETs also contribute to the activity of the tissue factor (TF)-driven extrinsic coagulation pathway. NET-associated TF and granular protease NE and cathepsin G inhibit the TF pathway inhibitor (TFPI). ${ }^{95,96}$ Activation of neutrophils with cytokines upregulates their TF mRNA expression and TF deposition on NETs. ${ }^{97}$ Furthermore, NETs contribute to mechanical clot stability by slowing down plasminogen-plasmin conversion by tissue plasminogen activator (t-PA) on clot surfaces. They also bind fibrin degradation peptides and delay their release from fibrin clots, as well as intercalate into fibrin fibers and delay plasmin-mediated lysis of plasma clots. ${ }^{98,99}$

Neutrophils and platelets interact with each other via platelet glycoprotein Ib $\alpha$ binding to neutrophil MAC-1 and platelet P-selectin binding to neutrophil P-selectin glycoprotein ligand-1 (PSGL-1). ${ }^{100-103}$ NETs promote coagulation in a platelet-dependent manner. High-resolution confocal intravital microscopy revealed that NET-triggered coagulation is a result of collaborative interaction between multiple components of NETs including DNA, histones and proteases with platelets, and platelet polyPs. Histone $\mathrm{H} 4$ on NETs perforates platelets causing the release of procoagulant polyP. ${ }^{94} \mathrm{Neu}-$ tralization of polyP with monoclonal blocking antibody (PP2055) significantly reduced NET-initiated thrombin formation in an experimental sepsis model. ${ }^{64}$ Furthermore, the procoagulant effect of NETs in PRP was attenuated by addition of bovine AP, providing additional evidence that polyP plays a role in the procoagulant activity of NETs. ${ }^{49}$ In an acute ST-segment elevation myocardial infarction model, platelet polyP led to NET formation by mTOR inhibition and autophagy induction. Treatment with IL-29 counteracted the effect of polyP on NET formation. ${ }^{104}$ Together, these studies indicate that polyP interacts with NETs and that the polyP-NETs crosstalk is important in coagulation.

Purified platelet and bacterial polyP exert high procoagulant activity even in the presence of inhibitors of the TF- driven extrinsic pathway. However, in the absence of FXII, polyP fails to trigger procoagulant activities. ${ }^{31}$ Consistent with polyP activities in human plasma, infusion of the polyanion into wild-type mice led to lethal pulmonary embolism, whereas FXII-deficient mice or mice treated with a FXII inhibitor were protected from polyP-triggered thrombosis. FXII, FXI, and FXII/FXI-double-deficient mice were similarly protected upon polyP-triggered thrombosis, indicating that polyP operates via the classical intrinsic coagulation pathway in vivo. ${ }^{31}$

\section{Therapeutic Targeting of NETs and polyP in Thrombosis}

NETs play a role in both arterial and venous thrombosis, making them an interesting target to reduce thrombosis or stimulate thrombolysis. There is a multitude of NET components (e.g., DNA, PAD4), cellular interactions (e.g., leukocyte-platelet/leukocyte-endothelium), and signaling pathways (e.g., leukocyte recruitment, NET formation/degradation), that are currently being investigated and that can be targeted pharmaceutically..$^{53}$ For instance, blocking platelet $\alpha$-granules or Weibel-Palade body release would hamper tethering of platelets and neutrophils to the vessel wall and also reduce leukocyte and platelet recruitment upon activation. ${ }^{105}$ Treating NET-containing thrombi from ischemic stroke patients ex vivo with t-PA resulted in partial thrombus dissolution, which was significantly accelerated upon the addition of DNase $1 .{ }^{105} \mathrm{~A}$ similar study showed that treating stroke thrombi with DNase1 alone does not efficiently resolve the thrombi. ${ }^{106}$ Thus, a combination treatment with a fibrinolytic agent, e.g., t-PA and/or ADAMTS13 (the protease specifically cleaving vWF), and a nuclease is recommended to obtain a sufficient degree of thrombolysis. Besides the recombinant human DNase1 (Dornase $\alpha$, Pulmozyme, Roche), which is approved for the treatment of cystic fibrosis, there are ongoing endeavors to develop improved NETdegrading nucleases. ${ }^{59}$ Furthermore, ongoing preclinical studies investigate PAD4 inhibitors as potential treatment options for multiple myeloma (BMS-P5, Bristol Myers Squibb ${ }^{107}$ ), rheumatoid arthritis, lung fibrosis, and thrombosis (preclinical PAD4 inhibitors program, Jubilant Therapeutics).

Based on the structural homology of DNA and polyP, nucleic acid-binding polymers were analyzed for interference with polyP-mediated coagulation. ${ }^{108}$ Polyamidoamine dendrimer, 1,4-diaminobutane core, generation 3 (PAMAM G-3) was shown to be the most effective polyP-binding molecule and reduced thrombus formation without increasing the risk of bleeding in both the $\mathrm{FeCl}_{3}$-induced carotid artery injury and collagen/epinephrine-induced pulmonary thromboembolism models. The notion that targeting polyP interferes with thrombosis while sparing hemostasis confirms that polyP exerts its procoagulant activity via FXII. FXII is the only coagulation factor that critically contributes to thrombosis but has no role in hemostatic mechanisms (reviewed in Renné and Stavrou ${ }^{109}$ ). Due to concerns regarding the significant toxicities of anti-polyP agents including dendrimers and other cationic small molecules, ${ }^{110,111}$ a new nontoxic, thromboprotective dendrimer-like cationic 
polyP-blocking compound class was introduced in 2016. Two of these novel universal heparin reversal agents (UHRAs), UHRA-9 and -10 , significantly reduced arterial thrombosis in vivo and did not indicate any signs of fibrinogen aggregates, inflammation, tissue damage, or necrosis. UHRA-9 and -10 also displayed a lower bleeding risk compared with therapeutic doses of heparin. In a more specific approach, recombinant E. coli Ppx was shown to specifically bind and degrade polyP. Targeting polyP with Ppx abolished polyP procoagulant activity in human plasma and in experimental thrombosis models in vivo while sparing hemostasis, demonstrating that polyP is procoagulant in a FXIIdependent manner in vivo. ${ }^{79}$

\section{Summary and Conclusions}

- NETs and polyP are physiologic polyanions with potent procoagulant activity.

- PolyP triggers coagulation by activating FXII, while both FXII- and TF-driven pathways contribute to NET-stimulated coagulation.

- The crosstalk between NETs and polyP plays an important role in coagulation and thrombosis.

- PolyP forms $\mathrm{Ca}^{2+}$-rich nanoparticles independently of the polyanion chain lengths that are retained on procoagulant platelet surfaces in vivo.

- DNase1 digests NETs in vivo and provides a promising strategy to therapeutically target NETs during thrombosis.

- Cationic nucleic acid-binding molecules, recombinant exopolyphosphatase mutants, and universal heparin reversal agent (UHRA) target polyP-driven thrombosis while sparing hemostasis, indicating that polyP functions via FXII activation in vivo.

\section{Authors' Contributions}

C.R., H.E., and T.R. wrote the manuscript. All authors edited the manuscript.

\section{Funding}

T.R. acknowledges the Deutsche Forschungsgemeinschaft (DFG, German Research Foundation) grants A11/SFB 877, B8/SFB 841, and P6/KFO 306.

Conflict of Interest

None declared.

\section{References}

1 Sobczak AIS, Pitt SJ, Stewart AJ. Glycosaminoglycan neutralization in coagulation control. Arterioscler Thromb Vasc Biol 2018; 38(06):1258-1270

2 Li W, Johnson DJ, Esmon CT, Huntington JA. Structure of the antithrombin-thrombin-heparin ternary complex reveals the antithrombotic mechanism of heparin. Nat Struct Mol Biol 2004;11(09):857-862

3 Mandel P, M'Etais P. Les acides nucléiques du plasma sanguin chez l'homme. C. R. Acad. Sci. Paris 1948;142:241-243

4 Razavi P, Li BT, Brown DN, et al. High-intensity sequencing reveals the sources of plasma circulating cell-free DNA variants. Nat Med 2019;25(12):1928-1937
5 Whittle E, Leonard MO, Harrison R, Gant TW, Tonge DP. Multimethod characterization of the human circulating microbiome. Front Microbiol 2019;9:3266

6 Davis GL Jr, Davis JS IV. Detection of circulating DNA by counterimmunoelectrophoresis (CIE). Arthritis Rheum 1973;16(01): 52-58

7 Diehl F, Schmidt K, Choti MA, et al. Circulating mutant DNA to assess tumor dynamics. Nat Med 2008;14(09):985-990

8 Leon SA, Shapiro B, Sklaroff DM, Yaros MJ. Free DNA in the serum of cancer patients and the effect of therapy. Cancer Res 1977;37 (03):646-650

9 Newman AM, Bratman SV, To J, et al. An ultrasensitive method for quantitating circulating tumor DNA with broad patient coverage. Nat Med 2014;20(05):548-554

10 Steinman CR. Free DNA in serum and plasma from normal adults. J Clin Invest 1975;56(02):512-515

11 Saffarzadeh M, Cabrera-Fuentes HA, Veit F, et al. Characterization of rapid neutrophil extracellular trap formation and its cooperation with phagocytosis in human neutrophils. Discoveries (Craiova) 2014;2(02):e19

12 Brinkmann V, Reichard U, Goosmann C, et al. Neutrophil extracellular traps kill bacteria. Science 2004;303(5663):1532-1535

13 Wang S, Xie T, Sun S, et al. DNase-1 treatment exerts protective effects in a rat model of intestinal ischemia-reperfusion injury. Sci Rep 2018;8(01):17788

14 Brinkmann V. Neutrophil extracellular traps in the second decade. J Innate Immun 2018;10(5-6):414-421

15 Castanheira FVS, Kubes P. Neutrophils and NETs in modulating acute and chronic inflammation. Blood 2019;133(20):2178-2185

16 Kaplan MJ, Radic M. Neutrophil extracellular traps: doubleedged swords of innate immunity. J Immunol 2012;189(06): 2689-2695

17 Fuchs TA, Abed U, Goosmann C, et al. Novel cell death program leads to neutrophil extracellular traps. J Cell Biol 2007;176(02): 231-241

18 Li P, Li M, Lindberg MR, Kennett MJ, Xiong N, Wang Y. PAD4 is essential for antibacterial innate immunity mediated by neutrophil extracellular traps. J Exp Med 2010;207(09):1853-1862

19 Papayannopoulos V, Metzler KD, Hakkim A, Zychlinsky A. Neutrophil elastase and myeloperoxidase regulate the formation of neutrophil extracellular traps. J Cell Biol 2010;191(03):677-691

20 Sollberger G, Choidas A, Burn GL, et al. Gasdermin D plays a vital role in the generation of neutrophil extracellular traps. Science Immunology 2018;3(26):eaar6689

21 Brown MR, Kornberg A. Inorganic polyphosphate in the origin and survival of species. Proc Natl Acad Sci U S A 2004;101(46): 16085-16087

22 Kornberg A. Inorganic polyphosphate: a molecule of many functions. Prog Mol Subcell Biol 1999;23:1-18

23 Arelaki S, Arampatzioglou A, Kambas K, Sivridis E, Giatromanolaki A, Ritis K. Mast cells co-expressing CD68 and inorganic polyphosphate are linked with colorectal cancer. PLoS One 2018; 13(03): $\mathrm{e} 0193089$

24 Hernández-Ruiz L, Sáez-Benito A, Pujol-Moix N, Rodríguez-Martorell J, Ruiz FA. Platelet inorganic polyphosphate decreases in patients with delta storage pool disease. J Thromb Haemost 2009;7(02):361-363

25 Kulakovskaya EV, Zemskova MY, Kulakovskaya TV. Inorganic polyphosphate and cancer. Biochemistry (Mosc) 2018;83(08): 961-968

26 Moreno-Sanchez D, Hernandez-Ruiz L, Ruiz FA, Docampo R. Polyphosphate is a novel pro-inflammatory regulator of mast cells and is located in acidocalcisomes. J Biol Chem 2012;287 (34):28435-28444

27 Nickel KF, Labberton L, Long AT, et al. The polyphosphate/factor XII pathway in cancer-associated thrombosis: novel perspectives for safe anticoagulation in patients with malignancies. Thromb Res 2016;141(Suppl 2):S4-S7 
28 Nickel KF, Ronquist G, Langer F, et al. The polyphosphate-factor XII pathway drives coagulation in prostate cancer-associated thrombosis. Blood 2015;126(11):1379-1389

29 Ruiz FA, Lea CR, Oldfield E, Docampo R. Human platelet dense granules contain polyphosphate and are similar to acidocalcisomes of bacteria and unicellular eukaryotes. J Biol Chem 2004; 279(43):44250-44257

30 Morrissey JH. Polyphosphate: a link between platelets, coagulation and inflammation. Int J Hematol 2012;95(04):346-352

31 Müller F, Mutch NJ, Schenk WA, et al. Platelet polyphosphates are proinflammatory and procoagulant mediators in vivo. Cell 2009; 139(06):1143-1156

32 Rendu F, Breton-Gorius J, Lebret M, et al. Evidence that abnormal platelet functions in human Chédiak-Higashi syndrome are the result of a lack of dense bodies. Am J Pathol 1983;111(03):307-314

33 Ghosh S, Shukla D, Suman K, et al. Inositol hexakisphosphate kinase 1 maintains hemostasis in mice by regulating platelet polyphosphate levels. Blood 2013;122(08):1478-1486

34 Mailer RK, Allende M, Heestermans M, et al. Xenotropic and polytropic retrovirus receptor 1 regulates procoagulant platelet polyphosphate. Blood 2020;137(10):1392-1405

35 Smith SA, Choi SH, Davis-Harrison R, et al. Polyphosphate exerts differential effects on blood clotting, depending on polymer size. Blood 2010;116(20):4353-4359

36 Momeni A, Filiaggi MJ. Comprehensive study of the chelation and coacervation of alkaline earth metals in the presence of sodium polyphosphate solution. Langmuir 2014;30(18):5256-5266

37 Donovan AJ, Kalkowski J, Smith SA, Morrissey JH, Liu Y. Sizecontrolled synthesis of granular polyphosphate nanoparticles at physiologic salt concentrations for blood clotting. Biomacromolecules 2014;15(11):3976-3984

38 Verhoef JJ, Barendrecht AD, Nickel KF, et al. Polyphosphate nanoparticles on the platelet surface trigger contact system activation. Blood 2017;129(12):1707-1717

39 Wijeyewickrema LC, Lameignere E, Hor L, et al. Polyphosphate is a novel cofactor for regulation of complement by a serpin, C1 inhibitor. Blood 2016;128(13):1766-1776

40 Labberton L, Long AT, Gendler SJ, et al. A flow cytometry-based assay for procoagulant platelet polyphosphate. Cytometry B Clin Cytom 2018;94(02):369-373

41 Castaldi PA, Larrieu MJ, Caen J. Availability of platelet factor 3 and activation of factor XII in thrombasthenia. Nature 1965;207 (995):422-424

42 Johne J, Blume C, Benz PM, et al. Platelets promote coagulation factor XII-mediated proteolytic cascade systems in plasma. Biol Chem 2006;387(02):173-178

43 Szymusiak M, Donovan AJ, Smith SA, et al. Colloidal confinement of polyphosphate on gold nanoparticles robustly activates the contact pathway of blood coagulation. Bioconjug Chem 2016;27 (01):102-109

44 Walsh PN, Griffin JH. Contributions of human platelets to the proteolytic activation of blood coagulation factors XII and XI. Blood 1981;57(01):106-118

45 Kleinschnitz C, Stoll G, Bendszus M, et al. Targeting coagulation factor XII provides protection from pathological thrombosis in cerebral ischemia without interfering with hemostasis. J Exp Med 2006;203(03):513-518

46 Renné T, Pozgajová M, Grüner S, et al. Defective thrombus formation in mice lacking coagulation factor XII. J Exp Med 2005;202(02):271-281

47 Döring Y, Libby P, Soehnlein O. Neutrophil extracellular traps participate in cardiovascular diseases: recent experimental and clinical insights. Circ Res 2020;126(09):1228-1241

48 Fuchs TA, Brill A, Duerschmied D, et al. Extracellular DNA traps promote thrombosis. Proc Natl Acad Sci U S A 2010;107(36): 15880-15885

49 Gould TJ, Vu TT, Swystun LL, et al. Neutrophil extracellular traps promote thrombin generation through platelet-dependent and platelet-independent mechanisms. Arterioscler Thromb Vasc Biol 2014;34(09):1977-1984

50 Kapoor S, Opneja A, Nayak L. The role of neutrophils in thrombosis. Thromb Res 2018;170:87-96

51 Laridan E, Martinod K, De Meyer SF. Neutrophil extracellular traps in arterial and venous thrombosis. Semin Thromb Hemost 2019;45(01):86-93

52 Maas C, Renné T Coagulation factor XII in thrombosis and inflammation. Blood 2018;131(17):1903-1909

53 Martinod K, Wagner DD. Thrombosis: tangled up in NETs. Blood 2014;123(18):2768-2776

54 Monroe DM. Polyphosphates rock! A role in thrombosis? Blood 2015;126(12):1403-1404

55 Brill A, Fuchs TA, Savchenko AS, et al. Neutrophil extracellular traps promote deep vein thrombosis in mice. J Thromb Haemost 2012;10(01):136-144

56 de Boer OJ, Li X, Teeling P, et al. Neutrophils, neutrophil extracellular traps and interleukin-17 associate with the organisation of thrombi in acute myocardial infarction. Thromb Haemost 2013;109(02):290-297

57 Ducroux C, Desilles JP, Ho-Tin-Noe B. Response by Ducroux et al to letter regarding article, "Thrombus neutrophil extracellular traps content impair tPA-induced thrombolysis in acute ischemic stroke". Stroke 2018;49(07):e266

58 Farkas AZ, Farkas VJ, Gubucz I, et al. Neutrophil extracellular traps in thrombi retrieved during interventional treatment of ischemic arterial diseases. Thromb Res 2019;175:46-52

59 Jiménez-Alcázar M, Rangaswamy C, Panda R, et al. Host DNases prevent vascular occlusion by neutrophil extracellular traps. Science 2017;358(6367):1202-1206

60 Kimball AS, Obi AT, Diaz JA, Henke PK. The emerging role of NETs in venous thrombosis and Immunothrombosis. Front Immunol 2016;7:236

61 Oehmcke S, Mörgelin M, Herwald H. Activation of the human contact system on neutrophil extracellular traps. J Innate Immun 2009; $1(03): 225-230$

62 von Brühl ML, Stark K, Steinhart A, et al. Monocytes, neutrophils, and platelets cooperate to initiate and propagate venous thrombosis in mice in vivo. J Exp Med 2012;209(04):819-835

63 Healy LD, Puy C, Itakura A, et al. Colocalization of neutrophils, extracellular DNA and coagulation factors during NETosis: development and utility of an immunofluorescence-based microscopy platform. J Immunol Methods 2016;435:77-84

64 McDonald B, Davis RP, Kim SJ, et al. Platelets and neutrophil extracellular traps collaborate to promote intravascular coagulation during sepsis in mice. Blood 2017;129(10):1357-1367

65 Noubouossie DF, Whelihan MF, Yu YB, et al. In vitro activation of coagulation by human neutrophil DNA and histone proteins but not neutrophil extracellular traps. Blood 2017;129(08): 1021-1029

66 Kolaczkowska E, Jenne CN, Surewaard BG, et al. Molecular mechanisms of NET formation and degradation revealed by intravital imaging in the liver vasculature. Nat Commun 2015; 6:6673

$67 \mathrm{Xu}$ J, Zhang X, Pelayo R, et al. Extracellular histones are major mediators of death in sepsis. Nat Med 2009;15(11):1318-1321

68 Saffarzadeh M, Juenemann C, Queisser MA, et al. Neutrophil extracellular traps directly induce epithelial and endothelial cell death: a predominant role of histones. PLoS One 2012;7(02):e32366

69 Lazzaretto B, Fadeel B. Intra- and extracellular degradation of neutrophil extracellular traps by macrophages and dendritic cells. J Immunol 2019;203(08):2276-2290

70 Farrera C, Fadeel B. Macrophage clearance of neutrophil extracellular traps is a silent process. J Immunol 2013;191(05): 2647-2656

71 Zhang H, Ishige K, Kornberg A. A polyphosphate kinase (PPK2) widely conserved in bacteria. Proc Natl Acad Sci U S A 2002;99 (26):16678-16683 
72 Akiyama M, Crooke E, Kornberg A. An exopolyphosphatase of Escherichia coli. The enzyme and its ppx gene in a polyphosphate operon. J Biol Chem 1993;268(01):633-639

73 Wurst H, Kornberg A. A soluble exopolyphosphatase of Saccharomyces cerevisiae. Purification and characterization. J Biol Chem 1994;269(15):10996-11001

74 Sethuraman A, Rao NN, Kornberg A. The endopolyphosphatase gene: essential in Saccharomyces cerevisiae. Proc Natl Acad Sci U S A 2001;98(15):8542-8547

75 Lonetti A, Szijgyarto Z, Bosch D, Loss O, Azevedo C, Saiardi A. Identification of an evolutionarily conserved family of inorganic polyphosphate endopolyphosphatases. J Biol Chem 2011;286 (37):31966-31974

76 Lorenz B, Schröder HC. Mammalian intestinal alkaline phosphatase acts as highly active exopolyphosphatase. Biochim Biophys Acta 2001;1547(02):254-261

77 Seidlmayer LK, Blatter LA, Pavlov E, Dedkova EN. Inorganic polyphosphate-an unusual suspect of the mitochondrial permeability transition mystery. Channels (Austin) 2012;6(06):463-467

78 Kannemeier C, Shibamiya A, Nakazawa F, et al. Extracellular RNA constitutes a natural procoagulant cofactor in blood coagulation. Proc Natl Acad Sci U S A 2007;104(15):6388-6393

79 Labberton L, Kenne E, Long AT, et al. Neutralizing blood-borne polyphosphate in vivo provides safe thromboprotection. Nat Commun 2016;7:12616

80 Mohanty T, Sørensen OE, Nordenfelt P. NETQUANT: automated quantification of neutrophil extracellular traps. Front Immunol 2018;8:1999

81 Gavillet M, Martinod K, Renella R, et al. Flow cytometric assay for direct quantification of neutrophil extracellular traps in blood samples. Am J Hematol 2015;90(12):1155-1158

82 Kessenbrock K, Krumbholz M, Schönermarck U, et al. Netting neutrophils in autoimmune small-vessel vasculitis. Nat Med 2009;15(06):623-625

83 Yipp BG, Petri B, Salina D, et al. Infection-induced NETosis is a dynamic process involving neutrophil multitasking in vivo. Nat Med 2012;18(09):1386-1393

84 Christ JJ, Willbold S, Blank LM. Methods for the analysis of polyphosphate in the life sciences. Anal Chem 2020;92(06): 4167-4176

85 Terashima M, Kamagata Y, Kato S. Rapid enrichment and isolation of polyphosphate-accumulating organisms through 4'6diamidino-2-phenylindole (DAPI) staining with fluorescenceactivated cell sorting (FACS). Front Microbiol 2020;11:793

86 Seki Y, Nitta K, Kaneko Y. Observation of polyphosphate bodies and DNA during the cell division cycle of Synechococcus elongatus PCC 7942. Plant Biol (Stuttg) 2014;16(01):258-263

87 Günther S, Trutnau M, Kleinsteuber S, et al. Dynamics of polyphosphate-accumulating bacteria in wastewater treatment plant microbial communities detected via DAPI $\left(4^{\prime}, 6^{\prime}\right.$-diamidino-2-phenylindole) and tetracycline labeling. Appl Environ Microbiol 2009;75(07):2111-2121

88 Diaz JM, Ingall ED. Fluorometric quantification of natural inorganic polyphosphate. Environ Sci Technol 2010;44(12): 4665-4671

89 Ohtomo R, Sekiguchi Y, Kojima T, Saito M. Different chain length specificity among three polyphosphate quantification methods. Anal Biochem 2008;383(02):210-216

90 Long AT, Kenne E, Jung R, Fuchs TA, Renné T Contact system revisited: an interface between inflammation, coagulation, and innate immunity. J Thromb Haemost 2016;14(03):427-437

91 Bender L, Weidmann H, Rose-John S, Renné T, Long AT. Factor XIIdriven inflammatory reactions with implications for anaphylaxis. Front Immunol 2017;8:1115

92 Weidmann H, Heikaus L, Long AT, Naudin C, Schlüter H, Renné T The plasma contact system, a protease cascade at the nexus of inflammation, coagulation and immunity. Biochim Biophys Acta Mol Cell Res 2017;1864(11, Pt B):2118-2127
93 Delabranche X, Helms J, Meziani F. Immunohaemostasis: a new view on haemostasis during sepsis. Ann Intensive Care 2017;7 (01):117

94 Semeraro F, Ammollo CT, Morrissey JH, et al. Extracellular histones promote thrombin generation through platelet-dependent mechanisms: involvement of platelet TLR2 and TLR4. Blood 2011;118(07):1952-1961

95 Massberg S, Grahl L, von Bruehl ML, et al. Reciprocal coupling of coagulation and innate immunity via neutrophil serine proteases. Nat Med 2010;16(08):887-896

96 Kalathottukaren MT, Haynes CA, Kizhakkedathu JN. Approaches to prevent bleeding associated with anticoagulants: current status and recent developments. Drug Deliv Transl Res 2018;8 (04):928-944

97 Folco EJ, Mawson TL, Vromman A, et al. Neutrophil extracellular traps induce endothelial cell activation and tissue factor production through interleukin- $1 \alpha$ and cathepsin G. Arterioscler Thromb Vasc Biol 2018;38(08):1901-1912

98 Longstaff C, Varjú I, Sótonyi P, et al. Mechanical stability and fibrinolytic resistance of clots containing fibrin, DNA, and histones. J Biol Chem 2013;288(10):6946-6956

99 Varjú I, Longstaff C, Szabó L, et al. DNA, histones and neutrophil extracellular traps exert anti-fibrinolytic effects in a plasma environment. Thromb Haemost 2015;113(06):1289-1298

100 Stark K, Philippi V, Stockhausen S, et al. Disulfide HMGB1 derived from platelets coordinates venous thrombosis in mice. Blood 2016;128(20):2435-2449

101 Hamburger SA, McEver RP. GMP-140 mediates adhesion of stimulated platelets to neutrophils. Blood 1990;75(03):550-554

102 Moore KL, Patel KD, Bruehl RE, et al. P-selectin glycoprotein ligand-1 mediates rolling of human neutrophils on P-selectin. J Cell Biol 1995;128(04):661-671

103 Simon DI, Chen Z, Xu H, et al. Platelet glycoprotein ibalpha is a counterreceptor for the leukocyte integrin Mac-1 (CD11b/CD18). J Exp Med 2000;192(02):193-204

104 Chrysanthopoulou A, Kambas K, Stakos D, et al. Interferon lambda1/IL-29 and inorganic polyphosphate are novel regulators of neutrophil-driven thromboinflammation. J Pathol 2017; 243(01):111-122

105 Carestia A, Kaufman T, Rivadeneyra L, et al. Mediators and molecular pathways involved in the regulation of neutrophil extracellular trap formation mediated by activated platelets. J Leukoc Biol 2016;99(01):153-162

106 Ducroux C, Di Meglio L, Loyau S, et al. Thrombus neutrophil extracellular traps content impair tPA-induced thrombolysis in acute ischemic stroke. Stroke 2018;49(03):754-757

107 Li M, Lin C, Deng H, et al. A novel peptidylarginine deiminase 4 (PAD4) inhibitor BMS-P5 blocks formation of neutrophil extracellular traps and delays progression of multiple myeloma. Mol Cancer Ther 2020;19(07):1530-1538

108 Jain S, Pitoc GA, Holl EK, et al. Nucleic acid scavengers inhibit thrombosis without increasing bleeding. Proc Natl Acad Sci U S A 2012;109(32):12938-12943

109 Renné T, Stavrou EX. Roles of factor XII in innate immunity. Front Immunol 2019;10:2011

110 Smith SA, Choi SH, Collins JN, Travers RJ, Cooley BC, Morrissey JH. Inhibition of polyphosphate as a novel strategy for preventing thrombosis and inflammation. Blood 2012;120(26):5103-5110

111 Travers RJ, Shenoi RA, Kalathottukaren MT, Kizhakkedathu JN, Morrissey JH. Nontoxic polyphosphate inhibitors reduce thrombosis while sparing hemostasis. Blood 2014;124(22):3183-3190

112 Chen G, Zhang D, Fuchs TA, Manwani D, Wagner DD, Frenette PS. Heme-induced neutrophil extracellular traps contribute to the pathogenesis of sickle cell disease. Blood 2014;123(24): 3818-3827

113 Clark SR, Ma AC, Tavener SA, et al. Platelet TLR4 activates neutrophil extracellular traps to ensnare bacteria in septic blood. Nat Med 2007;13(04):463-469 
114 Hoppenbrouwers T, Autar ASA, Sultan AR, et al. In vitro induction of NETosis: comprehensive live imaging comparison and systematic review. PLoS One 2017;12(05):e0176472

115 Nadesalingam A, Chen JHK, Farahvash A, Khan MA. Hypertonic saline suppresses NADPH oxidase-dependent neutrophil extracellular trap formation and promotes apoptosis. Front Immunol 2018;9:359

116 Zhang H, Gómez-García MR, Shi X, Rao NN, Kornberg A. Polyphosphate kinase 1 , a conserved bacterial enzyme, in a eukaryote, Dictyostelium discoideum, with a role in cytokinesis. Proc Natl Acad Sci U S A 2007;104(42):16486-16491

117 Hothorn M, Neumann H, Lenherr ED, et al. Catalytic core of a membrane-associated eukaryotic polyphosphate polymerase. Science 2009;324(5926):513-516

118 Ma AC, Kubes P. Platelets, neutrophils, and neutrophil extracellular traps (NETs) in sepsis. J Thromb Haemost 2008;6(03): 415-420

119 Maugeri N, Campana L, Gavina M, et al. Activated platelets present high mobility group box 1 to neutrophils, inducing autophagy and promoting the extrusion of neutrophil extracellular traps. J Thromb Haemost 2014;12(12):2074-2088

$120 \mathrm{Xu}$ J, Zhang X, Monestier M, Esmon NL, Esmon CT. Extracellular histones are mediators of death through TLR2 and TLR4 in mouse fatal liver injury. J Immunol 2011;187(05):2626-2631

121 de Bont CM, Boelens WC, Pruijn GJM. NETosis, complement, and coagulation: a triangular relationship. Cell Mol Immunol 2019; 16(01):19-27

122 Petersen LC, Bjørn SE, Nordfang O. Effect of leukocyte proteinases on tissue factor pathway inhibitor. Thromb Haemost 1992;67 (05):537-541

123 Thammavongsa V, Kim HK, Missiakas D, Schneewind O. Staphylococcal manipulation of host immune responses. Nat Rev Microbiol 2015;13(09):529-543

124 Kambas K, Chrysanthopoulou A, Vassilopoulos D, et al. Tissue factor expression in neutrophil extracellular traps and neutrophil derived microparticles in antineutrophil cytoplasmic antibody associated vasculitis may promote thromboinflammation and the thrombophilic state associated with the disease. Ann Rheum Dis 2014;73(10):1854-1863

125 Stakos DA, Kambas K, Konstantinidis T, et al. Expression of functional tissue factor by neutrophil extracellular traps in culprit artery of acute myocardial infarction. Eur Heart J 2015; 36(22):1405-1414

126 Grässle S, Huck V, Pappelbaum KI, et al. von Willebrand factor directly interacts with DNA from neutrophil extracellular traps. Arterioscler Thromb Vasc Biol 2014;34(07):1382-1389

127 Smith SA, Mutch NJ, Baskar D, Rohloff P, Docampo R, Morrissey $\mathrm{JH}$. Polyphosphate modulates blood coagulation and fibrinolysis. Proc Natl Acad Sci U S A 2006;103(04):903-908

128 Choi SH, Smith SA, Morrissey JH. Polyphosphate accelerates factor V activation by factor XIa. Thromb Haemost 2015;113 (03):599-604

129 Montilla M, Hernández-Ruiz L, García-Cozar FJ, Alvarez-Laderas I, Rodríguez-Martorell J, Ruiz FA. Polyphosphate binds to human von Willebrand factor in vivo and modulates its interaction with glycoprotein Ib. J Thromb Haemost 2012;10(11):2315-2323

130 Puy C, Tucker EI, Ivanov IS, et al. Platelet-derived short-chain polyphosphates enhance the inactivation of tissue factor pathway inhibitor by activated coagulation factor XI. PLoS One 2016; 11(10):e0165172

131 Mutch NJ, Engel R, Uitte de Willige S, Philippou H, Ariëns RA. Polyphosphate modifies the fibrin network and down-regulates fibrinolysis by attenuating binding of tPA and plasminogen to fibrin. Blood 2010;115(19):3980-3988

132 La CC, Takeuchi LE, Abbina S, Vappala S, Abbasi U, Kizhakkedathu JN. Targeting biological polyanions in blood: strategies toward the design of therapeutics. Biomacromolecules 2020;21(07): 2595-2621

133 Yousefi S, Gold JA, Andina N, et al. Catapult-like release of mitochondrial DNA by eosinophils contributes to antibacterial defense. Nat Med 2008;14(09):949-953

134 von Köckritz-Blickwede M, Goldmann O, Thulin P, et al. Phagocytosis-independent antimicrobial activity of mast cells by means of extracellular trap formation. Blood 2008;111(06): 3070-3080

135 Angelova PR, Iversen KZ, Teschemacher AG, Kasparov S, Gourine AV, Abramov AY. Signal transduction in astrocytes: Localization and release of inorganic polyphosphate. Glia 2018;66(10): 2126-2136

136 Gerasimaitė R, Mayer A. Ppn2, a novel $\mathrm{Zn}^{2+}$-dependent polyphosphatase in the acidocalcisome-like yeast vacuole. J Cell Sci 2017;130(09):1625-1636 